\title{
Kendali Optimal Model Diversifikasi Beras dan Non-beras dengan Target Akhir Konsumsi
}

\author{
Retno Wahyu Dewanti ${ }^{1}$ dan Subchan, M.Sc, Ph.D \\ ${ }^{1}$ Department of Mathematics and Information Technology, Institut Teknologi Kalimantan, \\ retnowahyu@itk.ac.id \\ ${ }^{2}$ Department of Mathematics and Information Technology, Institut Teknologi Kalimantan, \\ s.subchan@gmail.com
}

\begin{abstract}
Abstrak
Dalam Peraturan Presiden (Perpres) No. 22 Tahun 2009 disebutkan bahwa dua sasaran dari upaya diversifikasi pangan masyarakat Indonesia meliputi perbaikan pola konsumsi pangan yang beragam, bergizi, dan seimbang serta mengurangi konsumsi beras per kapita sebesar 1,5\% per tahun. Upaya tersebut dilakukan untuk menghindari ketergantungan pada satu jenis pangan pokok yaitu beras. Disisi lain ketersediaan pangan lokal merupakan alternatif terbaik sebagai pengganti beras karena lebih mudah dijangkau secara sik maupun ekonomi, seperti jagung, singkong, ubi jalar, sagu, gembili, yang biasa dikenal dengan istilah non-beras. Pada jurnal ini dibahas permasalahan kendali optimal model diversifikasi beras dan non-beras dengan penerapan target akhir konsumsi. Target akhir konsumsi adalah tingkat konsumsi beras dan non-beras yang diharapkan oleh pemerintah pada tahun yang sudah ditentukan. Model dinamik yang digunakan untuk mengintepretasikan adalah Model Lotka-Volterra. Persentase tingkat konsumsi beras dan non-beras dijadikan sebagai variabel pengendali yang bertujuan untuk meminimumkan biaya. Metode penyelesaian yang digunakan adalah Prinsip Minimum Pontryagin. Berdasarkan hasil simulasi ditunjukkan bahwa konsumsi beras menurun secara optimal sedangkan konsumsi non-beras meningkat, sehingga biaya yang dikeluarkan minimum.
\end{abstract}

Kata Kunci: Beras, non-beras, diversifikasi pangan, kendali optimal, Prinsip Minimum Pontryagin (PMP)

\section{Pendahuluan}

Tingginya dominasi beras pada pola konsumsi pangan penduduk Indonesia merupakan salah satu penyebab rendahnya kualitas pangan nasional. Sementara keberagaman jenis pangan dan keseimbangan gizi dalam pola konsumsi pangan sangat dibutuhkan untuk tetap bisa hidup sehat, aktif dan produktif. Diversifikasi pangan atau keanekaragaman konsumsi pangan menjadi penting untuk dilakukan guna mencapai kualitas konsumsi pangan yang lebih baik [1].

Dalam Peraturan Presiden (Perpres) No. 22 Tahun 2009 disebutkan bahwa dua sasaran dari upaya diversifikasi pangan masyarakat Indonesia meliputi perbaikan pola konsumsi pangan yang beragam, bergizi, dan seimbang serta mengurangi konsumsi beras per kapita sebesar $1,5 \%$ per tahun. Disisi lain ketersediaan pangan lokal merupakan alternatif terbaik sebagai pengganti beras sebagai sumber karbohidrat karena lebih mudah dijangkau secara fisik maupun ekonomi, seperti jagung, singkong, ubi jalar, sagu, gembili, yang biasa dikenal dengan istilah non-beras. Karbohidrat non-beras dapat diproduksi secara lokal dengan biaya yang murah dan mudah dengan kandungan gizi yang tidak kalah dengan beras [1].

Upaya terwujudnya diversifikasi konsumsi pangan dilakukan pemerintah dengan penetapan target pencapaian angka konsumsi beras dan non-beras di akhir tahun yang telah ditentukan. Hal ini tertuang dalam roadmap diversifikasi badan ketahanan pangan kementerian pertanian RI tahun 2012. Perlu dukungan dan sinergi kegiatan lintas sektor serta peran aktif pembuat kebijakan, pelaku usaha, peneliti dan berbagai pihak yang peduli terhadap ketahanan pangan berbasis sumberdaya lokal [2].

Jurnal ini menerapkan teori kendali optimal pada permasalahan diversi kasi konsumsi beras dan non-beras. Penelitian serupa pernah dilakukan Miah, M. S., Ahmed, N. U., Chowdhury, M. (2011) dengan menerapkan model Lotka Volterra yang membahas mengenai kendali optimal dalam produksi sumber energi [3]. Selain itu, saya pernah mengikuti seminar yang membahas mengenai hal yang sama, yaitu model diversifikasi beras dan non-beras tetapi tanpa target akhir konsumsi [6]. Penelitian ini bertujuan untuk mengoptimalkan tingkat konsumsi beras dan non-beras dengan adanya target akhir konsumsi sehingga mampu meminimumkan biaya. Studi kasus dalam penelitian ini menggunakan statistik konsumsi pangan tahun 2012. 


\section{Metodologi}

\subsection{Model Matematika dari Sistem Dinamik Beras dan Non-Beras}

Formulasi model diversifikasi beras dan non-beras merujuk pada model prosiding diversifikasi tanpa target akhir [6]. Sehingga model matematika dituliskan sebagai berikut :

$$
\begin{aligned}
& \dot{x}_{1}=\frac{d x_{1}}{d t}=\alpha_{1} x_{1}-\beta_{1} x_{1} x_{2} \\
& \dot{x}_{2}=\frac{d x_{2}}{d t}=a_{2} x_{2}-\beta_{2} x_{1} x_{2}
\end{aligned}
$$

Dalam jangka waktu $I=\left[t_{0}, t_{f}\right]$. Untuk $t \in I$.

$x_{1}(t)$ : tingkat konsumsi beras pada waktu $t$

$x_{2}(t)$ : tingkat konsumsi non-beras pada waktu $t$

$\alpha_{1}(t)$ : persentase tingkat pertumbuhan dalam konsumsi beras

$\alpha_{2}(t)$ : persentase tingkat pertumbuhan dalam konsumsi non-beras

$\beta_{1}(t)$ : konstanta positif yang merepresentasikan dampak yang berpengaruh pada konsumsi beras akibat adanya persaingan dengan tingkat konsumsi non-beras

$\beta_{2}(t)$ : konstanta positif yang merepresentasikan dampak yang berpengaruh pada konsumsi non-beras akibat adanya persaingan dengan tingkat konsumsi beras.

Dalam mengendalikan tingkat konsumsi beras dan non-beras, $\alpha_{1}(t)$ dan $\alpha_{2}(t)$ diasumsikan sebagai variabel pengendali $u_{1}(t)$ dan $u_{2}(t)$ pada interval $I=\left[t_{0}, t_{f}\right][3]$.

$$
\begin{aligned}
& \dot{x}_{1}=\frac{d x_{1}}{d t}=u_{1}(t) x_{1}(t)-\beta_{1} x_{1}(t) x_{2}(t) \\
& \dot{x}_{2}=\frac{d x_{2}}{d t}=u_{2}(t) x_{2}(t)-\beta_{2} x_{1}(t) x_{2}(t)
\end{aligned}
$$

dimana $u_{1}(t)$ dan $u_{2}(t)$ berada dalam interval $[-1,1]$.

$U=u=\left(u_{1}(t), u_{2}(t)\right) \in R^{2} ;-1 \leq u_{1}(t), u_{2}(t) \leq 1 \subset R^{2}$

dengan angka 1 pada interval tersebut mewakili nilai $100 \%$ dan untuk tanda minus secara fisis menunjukkan tingkat penurunan.

\subsection{Model Matematika dan Fungsi Tujuan}

Pada seminar sebelumnya, telah dibahas mengenai permasalahan kendali optimal untuk meminimumkan biaya tanpa target akhir. Pada jurnal ini dibahas permasalahan kendali optimal untuk meminimumkan biaya dengan target akhir. Formulasi fungsi tujuan dinyatakan dalam model matematika tiga suku, suku pertama adalah fungsi biaya yang menyatakan selisih tingkat konsumsi dan tingkat ketersediaan. Suku kedua menunjukkan fungsi biaya yang berhubungan dengan usaha pengendalian tingkat konsumsi beras dan non-beras. Kemudian yang terakhir fungsi biaya yang diakibatkan adanya selisih antara tingkat konsumsi beras dan non-beras di akhir periode dengan target konsumsi di akhir periode [3].

$$
\begin{gathered}
I(u)=\frac{1}{2} \int_{t_{0}}^{t_{f}}\left\{w_{1}\left(x_{1}(t)-x_{1}^{s}(t)\right)^{2}+w_{2}\left(x_{2}(t)-x_{2}^{s}(t)\right)^{2}\right\} d t+ \\
\frac{1}{2} \int_{t_{0}}^{t_{f}}\left\{q_{1} u_{1}^{2}+q_{2} u_{2}^{2}\right\} d t+ \\
\frac{1}{2} \int_{t_{0}}^{t_{f}}\left\{v_{1}\left(x_{1}\left(t_{f}\right)-x_{1}^{s}\left(t_{f}\right)\right)^{2}+v_{2}\left(x_{2}\left(t_{f}\right)-x_{2}^{s}\left(t_{f}\right)\right)^{2}\right\} d t
\end{gathered}
$$

$w_{1} \quad$ : bobot biaya penyimpangan tingkat konsumsi dengan persediaan beras

$w_{2} \quad$ : bobot biaya penyimpangan tingkat konsumsi dengan persediaan non-beras 
$x_{1}^{s}(t)$ : tingkat persediaan beras waktu $t$

$x_{2}^{s}(t)$ : tingkat persediaan non-beras pada waktu $t$

$q_{1} \quad$ : bobot biaya pengendalian ketergantungan terhadap konsumsi beras

$q_{2}$ : bobot biaya pengendalian ketergantungan terhadap konsumsi non-beras

$v_{1} \quad$ : bobot biaya penyimpangan tingkat konsumsi beras

dengan target konsumsinya di akhir periode, $v_{1}>0$

$v_{2} \quad$ : bobot biaya penyimpangan tingkat konsumsi non-beras

dengan target konsumsinya di akhir periode, $v_{2}>0$

$x_{1}\left(t_{f}\right)$ : tingkat konsumsi beras pada waktu akhir

$x_{2}\left(t_{f}\right)$ : tingkat konsumsi non-beras pada waktu akhir

$x_{1}^{z}\left(t_{f}\right)$ : target akhir konsumsi beras

$x_{2}\left(t_{f}\right)$ : target akhir konsumsi non-beras

\section{Hasil dan Pembahasan}

\subsection{Penyelesaian Kendali Optimal}

Formulasi kendali optimal dengan fungsi objektif yang diberikan pada Persamaan (5), diperoleh fungsi Hamiltonian sebagai berikut:

$$
\begin{aligned}
& H=\frac{1}{2} w_{1} x_{1}^{2}(t)-w_{1} x_{1}(t) x_{1}^{s}(t)+\frac{1}{2} w_{1}\left(x_{1}^{s}\right)^{2}+ \\
& \frac{1}{2} w_{2} x_{2}^{2}(t)-w_{2} x_{2}(t) x_{2}^{s}(t)+\frac{1}{2} w_{2}\left(x_{2}^{s}\right)^{2}+ \\
& \frac{1}{2} q_{1} u_{1}^{2}+\frac{1}{2} q_{2} u_{2}^{2}+ \\
& \lambda_{1}(t) u_{1}(t) x_{1}(t)-\beta_{1} \lambda_{1}(t) x_{1}(t) x_{2}(t)+ \\
& \lambda_{2}(t) u_{2}(t) x_{2}(t)-\beta_{2} \lambda_{2}(t) x_{1}(t) x_{2}(t)
\end{aligned}
$$

Langkah berikutnya menentukan kondisi stasioner dari Persamaan (6) untuk mendapatkan kendali optimal u. Diperoleh persamaan kendali optimal yaitu:

$$
\begin{aligned}
& u_{1}^{*}(t)=-\frac{\lambda_{1}(t) x_{1}(t)}{q_{1}} \\
& u_{2}^{*}(t)=-\frac{\lambda_{2}(t) x_{2}(t)}{q_{2}}
\end{aligned}
$$

Karena kendali optimal berada pada interval $[-1,1]$, maka kendali optimal $u_{1}^{*}(t)$ dan $u_{2}^{*}(t)$ diperoleh berada dalam interval tersebut.

Selanjutnya dilakukan uji turunan kedua untuk menunjukkan bahwa $H$ mempunyai minimum di $u(t)$.

$$
\begin{aligned}
& \frac{\partial^{2} H}{\partial U_{1}^{2}}=q_{1}>0 \\
& \frac{\partial^{2} H}{\partial U_{2}^{2}}=q_{2}>0 \\
& u_{1}^{*}(t)=\operatorname{maks}\left\{\min \left\{-\frac{\lambda_{1}(t) x_{1}(t)}{q_{1}}, 1\right\},-1\right\} \\
& u_{2}^{*}(t)=\operatorname{maks}\left\{\min \left\{-\frac{\lambda_{2}(t) x_{2}(t)}{q_{2}}, 1\right\},-1\right\}
\end{aligned}
$$


Karena turunan kedua $H$ terhadap semua pengendali bernilai positif, maka uji turunan kedua terpenuhi, sehingga $H$ mempunyai minimum di $u_{1}(t)$ dan $u_{2}(t)$.

Tahap selanjutnya dilakukan substitusi Persamaan (7) dan Persamaan (8) ke Persamaan (6), sehingga didapat persamaan Hamiltonian yang baru yaitu:

$$
\begin{aligned}
& H^{*}=\frac{1}{2} w_{1} x_{1}^{2}(t)-w_{1} x_{1}(t) x_{1}^{s}(t)+\frac{1}{2} w_{1}\left(x_{1}^{s}\right)^{2}+ \\
& \frac{1}{2} w_{2} x_{2}^{2}(t)-w_{2} x_{2}(t) x_{2}^{s}(t)+\frac{1}{2} w_{2}\left(x_{2}^{s}\right)^{2}- \\
& \frac{\lambda_{1}^{2}(t) x_{1}^{2}(t)}{2 q_{1}}-\beta_{1} \lambda_{1}(t) x_{1}(t) x_{2}(t)- \\
& \frac{\lambda_{2}^{2}(t) x_{2}^{2}(t)}{2 q_{2}}-\beta_{2} \lambda_{2}(t) x_{1}(t) x_{2}(t)
\end{aligned}
$$

Selanjutnya Persamaan (9) digunakan untuk mendapatkan persamaan state dan costate yang optimal, diperoleh sistem persamaan diferensial sebagai berikut:

$$
\begin{aligned}
& \dot{x}_{1}(t)=-\frac{\lambda_{1}(t) x_{1}^{2}(t)}{q_{1}}-\beta_{1} x_{1}(t) x_{2}(t) \\
& \dot{x}_{2}(t)=-\frac{\lambda_{2}(t) x_{2}(t)}{q_{2}}-\beta_{2} x_{1}(t) x_{2}(t) \\
& \lambda_{1}(t)-\frac{\lambda_{1}^{2}(t) x_{1}(t)}{q_{1}}+\beta_{1} \lambda_{1}(t) x_{2}(t)+ \\
& \beta_{2} \lambda_{2}(t) x_{2}(t)-w_{1}\left(x_{1}(t)-x_{1}^{s}(t)\right) \\
& \lambda_{2}(t)=\frac{\lambda_{2}^{2}(t) x_{2}(t)}{q_{2}}+\beta_{1} \lambda_{1}(t) x_{1}(t)+ \\
& \beta_{2} \lambda_{2}(t) x_{1}(t)-w_{2}\left(x_{2}(t)-x_{2}^{s}(t)\right)
\end{aligned}
$$

Diasumsikan bahwa laju pertumbuhan persediaan non-beras setiap waktu selalu meningkat seiring pertumbuhan penduduk yaitu

$$
\frac{d}{d t} x_{2}^{s}(t)=\mu x_{2}^{s}(t)
$$

dengan $\mu$ adalah konstata tak negatif. Dengan penyelesaian dari persamaan diferensial (11) adalah sebagai berikut:

$x_{2}^{s}(t)=x_{2}^{s}(0) e^{\mu t}$

Karena peningkatan jumlah penduduk tidak sebanding dengan kapasitas produksi beras. Berdasarkan pada hal tersebut, diasumsikan bahwa tingkat persediaan beras menurun secara eksponensial, sehingga dapat dinyatakan sebagai berikut:

$x_{1}^{s}(t)=x_{1}^{s}(0) e^{-\gamma t} \geq 0$ 
Jika diberikan asumsi bahwa tingkat ketersediaan awal bernilai sama dengan tingkat konsumsi awal, sehingga

$x_{1}^{s}(t)=x_{1}(0)$

$x_{2}^{s}(t)=x_{2}(0)$

Maka diperoleh persamaan tingkat adalah persediaan beras dan non-beras sebagai berikut :

$x_{1}^{s}(t)=x_{1}(0) e^{-y t}$

$x_{2}^{s}(t)=x_{2}(0) e^{-\mu t}$

Dengan demikian, diperoleh sistem persamaan diferensial baru yang akan diselesaikan yaitu sebagai berikut:

$\dot{x}_{1}(t)=-\frac{\lambda_{1}(t) x_{1}^{2}(t)}{q_{1}}-\beta_{1} x_{1}(t) x_{2}(t)$

$\tilde{x}_{2}(t)=-\frac{\lambda_{2}(t) x_{2}(t)}{q_{2}}-\beta_{2} x_{1}(t) x_{2}(t)$

$\lambda_{1}(t)=\beta_{1} \lambda_{1}(t) x_{2}(t)+\beta_{2} \lambda_{2}(t) x_{2}(t)+\frac{\lambda_{1}^{2}(t) x_{1}(t)}{q_{1}}-$

$u_{1}\left(x_{1}(t)-\left(x_{1}(0) e^{-v t}\right)\right)$

$\lambda_{2}(t)=\beta_{1} \lambda_{1}(t) x_{1}(t)+\beta_{2} \lambda_{2}(t) x_{1}(t)+\frac{\lambda_{2}^{2}(t) x_{2}(t)}{q_{2}}-$

$w_{2}\left(x_{2}(t)-\left(x_{2}(0) e^{\mu t}\right)\right)$

dengan kondisi awal adalah : $x_{1}\left(t_{0}\right)=x_{1}(0)$ dan : $x_{2}\left(t_{0}\right)=x_{2}(0)$ dan kondisi transversaliti sebagai berikut [5]:

$\lambda^{*}\left(t_{f}\right)=\left(\frac{\partial \Phi}{\partial x}\right)_{*} t_{f}$

dengan $\Phi$ didefinisikan sebagai berikut:

$$
\begin{aligned}
& \Phi=\frac{1}{2}\left\{v_{1}\left(x_{1}\left(t_{f}\right)-x_{1}^{z}\left(t_{f}\right)\right)^{2}+v_{2}\left(x_{2}\left(t_{f}\right)-x_{2}^{s}\left(t_{f}\right)\right)^{2}\right\} \\
& =\frac{1}{2}\left\{v_{1}\left(x_{1}^{2}\left(t_{f}\right)-2 x_{1}\left(t_{f}\right) x_{1}^{s}\left(t_{f}\right)+\left(x_{1}^{s}\left(t_{f}\right)\right)^{2}\right)+\right. \\
& v_{2}\left(x_{2}^{2}\left(t_{f}\right)-2 x_{2}\left(t_{f}\right) x_{2}^{s}\left(t_{f}\right)+\left(x_{2}^{s}\left(t_{f}\right)\right)^{2}\right\} \\
& =\frac{1}{2} v_{1} x_{1}^{2}\left(t_{f}\right)-v_{1} x_{1}\left(t_{f}\right) x_{1}^{s}\left(t_{f}\right)+\frac{1}{2} v_{1}\left(x_{1}^{s}\left(t_{f}\right)\right)^{2}+ \\
& \frac{1}{2} v_{2} x_{2}^{2}\left(t_{f}\right)-v_{2} x_{2}\left(t_{f}\right) x_{2}^{s}\left(t_{f}\right)+\frac{1}{2} v_{2}\left(x_{2}^{s}\left(t_{f}\right)\right)^{2}
\end{aligned}
$$

sehingga diperoleh: 


$$
\begin{aligned}
& \lambda_{1}^{s}\left(t_{f}\right)=\left(\frac{\partial \Phi}{\partial x_{1}}\right) \\
& =v_{1} x_{1}\left(t_{f}\right)-v_{1} x_{1}^{s}\left(t_{f}\right) \\
& =v_{1}\left(x_{1}\left(t_{f}\right)-x_{1}^{s}\left(t_{f}\right)\right) \\
& \lambda_{2}^{s}\left(t_{f}\right)=\left(\frac{\partial \Phi}{\partial x_{2}}\right) \\
& =v_{2} x_{2}\left(t_{f}\right)-v_{2} x_{2}^{s}\left(t_{f}\right) \\
& =v_{2}\left(x_{2}\left(t_{f}\right)-x_{2}^{s}\left(t_{f}\right)\right)
\end{aligned}
$$

\begin{tabular}{|c|c|}
\hline Parameter & Nilai \\
\hline$w_{1}$ & 0,64 \\
\hline$w_{2}$ & 0,36 \\
\hline$q_{1}$ & 0,66 \\
\hline$q_{2}$ & 0,34 \\
\hline$v_{1}$ & 0,66 \\
\hline$v_{2}$ & 0,34 \\
\hline$x_{1}(0)$ & 100,8 \\
\hline$x_{2}(0)$ & 16,3 \\
\hline $\overrightarrow{x_{1}}$ & 93,4 \\
\hline $\overrightarrow{\bar{x}_{2}^{s}}$ & 20,7 \\
\hline
\end{tabular}

Selanjutnya, permasalahan ini diselesaikan secara numerik menggunakan fungsi Bvp4c [7].

\section{Simulasi Numerik}

Adapun nilai parameter yang digunakan seperti pada tabel berikut:

Tabel 1. Parameter input

Tabel 2. Parameter Komputasi

\begin{tabular}{|c|c|c|c|c|c|}
\hline Parameter & $t_{f}$ & $\beta_{1}$ & $\beta_{2}$ & $\mu$ & $\gamma$ \\
\hline Nilai & 1 & 0,005 & 0,011 & 0,05 & 0,015 \\
\hline
\end{tabular}

Simulasi pertama menunjukkan perilaku tingkat konsumsi beras dan non-beras tanpa pengendali selama 1 tahun. Gambar. 1 terlihat bahwa tingkat konsumsi beras meningkat dan tingkat konsumsi non-beras mengalami penurunan. Tingkat konsumsi awal beras sebesar 100,8 $\mathrm{Kg} / \mathrm{kapita} /$ tahun, dan pada tahun pertama mencapai $101,5487 \mathrm{Kg} / \mathrm{kapita} /$ tahun sedangkan tingkat konsumsi non-beras menurun dari $16,3 \mathrm{Kg} / \mathrm{kapita} /$ tahun menjadi $13,3453 \mathrm{Kg} / \mathrm{kapita} / \mathrm{tah}$. Hal ini dikarenakan tidak adanya pengendali sehingga laju perubahan konsumsi beras dan non-beras bersifat natural sesuai dengan kebiasaan masyarakat. Padahal tingkat persediaan beras mengalami penurunan seiring dengan pertumbuhan penduduk, hal ini menyebabkan perbedaan yang sangat besar antara tingkat konsumsi dan persediaan, seperti yang terlihat pada gambar 2. Dari gambar 2 dapat dilihat bahwa perbedaan diantara tingkat konsumsi dan persediaan sangat besar. Dari grafik tersebut terlihat bahwa tingkat konsumsi beras semakin meningkat, sedangkan tingkat persediaannya mengalami penurunan. 

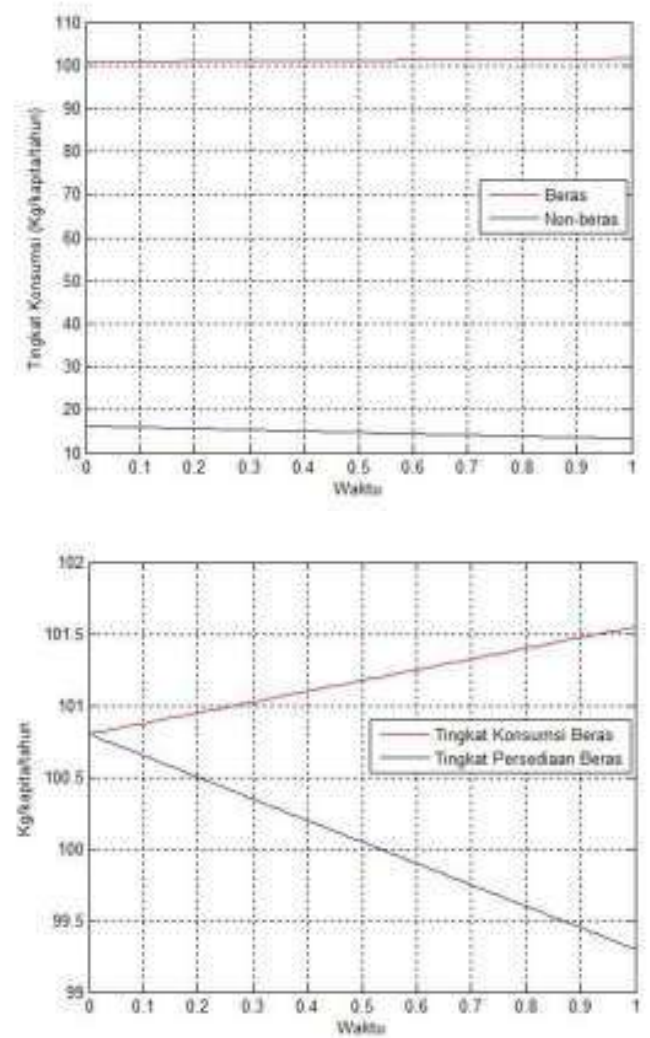

Gambar 2. Tingkat Persediaan dan Tingkat Konsumsi Beras Tanpa Pengendali

Simulasi selanjutnya dengan pengendali, gambar 3 menunjukkan tingkat konsumsi beras dan non-beras yang optimal selama 1 tahun. Grafik tersebut memperlihatkan bahwa tingkat konsumsi beras mengalami penurunan, dari konsumsi awal sebesar 100,8 Kg/kapita/tahun menjadi 99,2993 Kg/ kapita/tahun. Selisih yang dihasilkan dengan target akhir konsumsi adalah 0,0007 atau 0,07\%. Sementara itu, tingkat konsumsi non-beras selama 1 tahun mengalami peningkatan, dari nilai awal $16,3 \mathrm{Kg} / \mathrm{kapita} /$ tahun menjadi 16,9941 Kg/kapita/tahun. Dari informasi tersebut, terlihat bahwa selisih antara tingkat konsumsi akhir yang diperoleh dengan target akhir konsumsinya cukup kecil, yaitu 0,0059 atau $0,59 \%$. Hasil ini menunjukkan bahwa tingkat konsumsi beras dan non-beras dikendalikan secara optimal sehingga mampu mendekati target akhir konsumsi yang ditargetkan. Kemudian gambar 4 merupakan grafik pengendali optimal tingkat persediaan dan tingkat konsumsi beras.

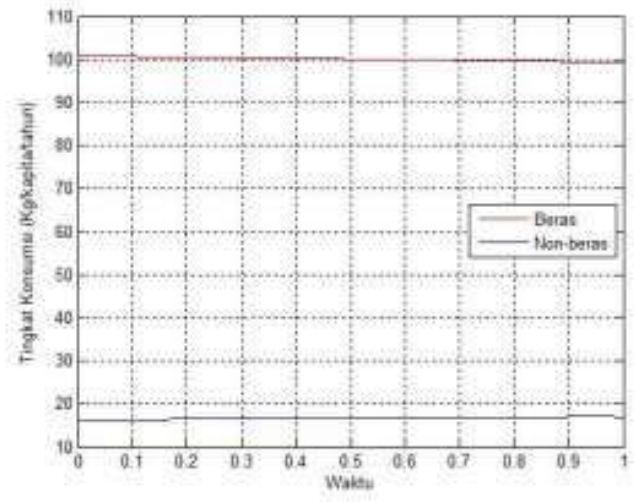

Gambar 3. Tingkat Konsumsi Beras dan Non-beras dengan Pengendalian 


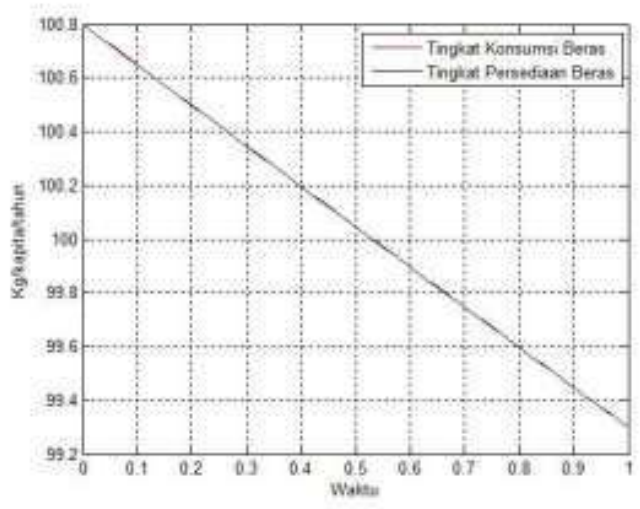

Gambar 4. Tingkat Persediaan dan Tingkat Konsumsi Beras dengan Pengendali

Grafik tersebut menunjukkan bahwa dengan adanya pengendali tingkat konsumsi beras dapat ditekan sehingga tingkat persediaan mampu memenuhi tingkat konsumsi beras secara optimal. Gambar 5 menunjukkan grafik dari pengendali tingkat konsumsi beras $\left(u_{1}(t)\right)$ dan non-beras $\left(u_{2}(t)\right)$. Dari grafik tersebut, terlihat bahwa kedua pengendali yang didapat berada dalam interval $[-1,1]$. Persentase tingkat pertumbuhan dari konsumsi beras lebih kecil dari persentase tingkat pertumbuhan konsumsi non-beras. Sedangkan persentase tingkat pertumbuhan dari konsumsi non-beras pada awalnya meningkat, kemudian mendekati akhir periode persentase pertumbuhannya menurun mendekati target yang telah ditargetkan.

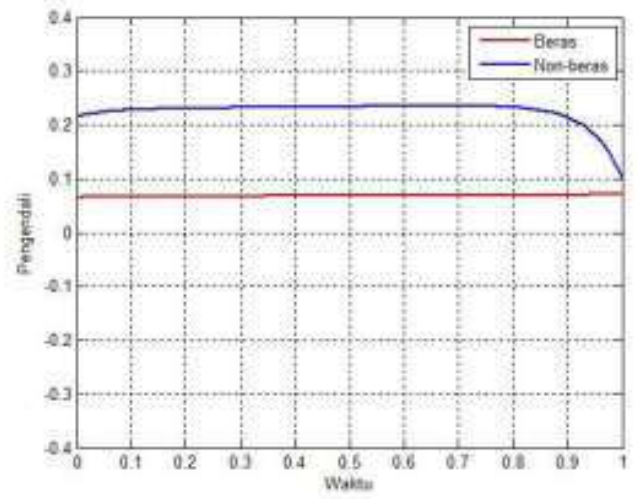

Gambar 5. Pengendali Optimal

\section{Kesimpulan}

Berdasarkan analisis dan pembahasan dapat disimpulkan beberapa hal sebagai berikut.

1. Dengan diterapkan teori kendali optimal menggunakan Prinsip Minimum Pontryagin diperoleh pengendali optimal dalam konsumsi beras dan non-beras.

2. Berdasarkan hasil simulasi ditunjukkan bahwa konsumsi beras menurun secara optimal sementara konsumsi non-beras meningkat, sehingga biaya yang dikeluarkan minimum.

\section{Daftar Pustaka}

Badan Ketahanan Pangan Kementerian Pertanian RI. (2012) Roadmap Diversi kasi Pangan Tahun 2011-2015, Kementerian Pertanian, Jakarta.

Martianto, Drajat., Briawan, Dodik., dkk. (2009) Percepatan Diversi kasi Konsumsi Pangan Berbasis Pangan Lokal : Perspektif Pejabat Daerah dan Strategi Pencapaiannya, Jurnal Gizi dan Pangan, Vol.4 No.3:123-131. 
Miah, M. S. and Ahmed, N. U. and Chowdhury, M. (2011) Optimum Policy for Integration of Renewable Energy Sources into the Power Generation System, Energy Economics, 34, 558-567.

Murray, J. D. (2002) Mathematical Biology I: An Introduction, New York.

Naidu, S. D. (2002) Optimal Control System, CRC Press LLC, USA.

Retno Wahyu Dewanti dan S. Subchan. (2014) Kendali optimal Model Diversi kasi Beras dan Non-beras, Prosiding Konferensi Nasional Matematika, ITS, Surabaya.

Shampine, L.F. and Kierzenk, J. and Reichelt, M.W. (2000) Solving Boundary Value Problems for Ordinary Di erential Equations in Matlab with BVP4C, Massachusetts Institute Of Technology, USA. 